\title{
Study on The Mode of the Basic Level Government Purchasing the Aged Service — A Case Study of Beijing, Shunyi District \\ Geng Ge Feng
}

Zao Zhuang University, Zao Zhuang, China

email: ggf1403@126.com

Key words: government purchase; pension service; social organization; model

\begin{abstract}
. with the trend of population aging, the grass-roots government is facing a heavy burden of pension. In recent years, social organizations continue to grow and develop, social organizations use their own advantages, and actively participate in the pension services. The basic level government purchases the service to the social organization is one kind of practice exploration. In this paper, the basic level of the government to the social organizations to purchase pension service model of the system. Shunyi District pension services in Beijing, for example, the government and social organizations to provide cooperation with the provision of pension services fresh material. And summarizes the experience which is worth learning from.
\end{abstract}

\section{基层政府购买养老服务的模式探究 一以北京市顺义区为例

\author{
耿格峰 \\ 楒庄学院政治与社会发展学院, 本庄, 山东, 中国 \\ ggf1403@126.com
}

关键词：政府购买；养老服务；社会组织；模式

\begin{abstract}
摘要：随着人口老龄化趋势的加剧，基层政府面临着沉重的养老负担。近年来，社会组织不 断发展壮大，社会组织利用自身的优势，积极参与到养老服务之中。基层政府向社会组织购 买服务是一种实践探索。本文对基层政府向社会组织购买养老服务的模式进行了系统阐述。 以北京市顺义区养老服务为例, 对政府与社会组织合作供给养老服务提供了鲜活的素材。并 总结了其中值得借鉴的经验。
\end{abstract}

\section{1.引言}

\section{1 研究背景与问题的提出}

21 世纪中国人口面临着老龄化的挑战。根据《2016 年中国老龄事业发展统计报告》的相关 数据显示, 截止 2016 年底, 全国 65 岁以上老年人口达 1.1883 亿, 老年抚养比为 $11.9 \%$, 较 上年末上升 0.3 个百分点。根据《北京市“十三五”时期老龄事业发展规划》, 截止 2016 年底, 北京全市 60 岁以上户籍老年任由约 31.3 万, 占总人口的 $23.4 \%$, 到 2020 年北京常住老年人 口将超过 400 万人。北京作为中国的首都, 不仅经济发展迅速, 老龄化程度居全国第二。由 此可见, 如何解决北京市养老服务的供给难题, 面对“未富先老”的现状, 缓解城市现代化发 
展过程中老龄化压力, 是政府和社会各界关注的重要课题。

\section{2 文献综述}

伴随着中国政府治理理念和政策的转型，政府购买服务已经成为提供公共服务的一种重 要形式。养老服务是一种典型的公共服务, 养老服务也是较早实行政府购买服务的领域之一。 政府购买服务是将原来由政府直接提供的、为社会公共服务的事项交给有资质的社会组织或 市场机构来完成，根据提供服务的数量和质量，按照一定的标准进行评估后支付服务费用。 尤其是在 2010 年以来, 国务院各部委先后出台了鼓励民间投资的法律文件。2010 年 3 月, 《国 务院关于鼓励和引导民间投资健康发展的若干意见》内容包括了 12 部分 36 条, 规范了民间 投资的领域和范围，其中的第 16 条提出“鼓励民间资本参与发展社会福利事业”。2014 年 8 月，《关于做好政府购买养老服务工作的通知》(财社[2014]105 号) 把政府购买服务与满足老 年人的养老需求相结合, 明确了购买的基本原则和工作目标, 规范购买流程、健全监管机制。 对“谁来买、买什么、为谁买、向谁买、怎么买”进行了进一步说明。2015 年 1 月, 财政部印 发的《政府购买服务暂行管理办法》进一步细化了“购买方式程序、预算及财务管理、绩效和 监督管理”，政府购买服务以民生为主题，并且突出公共性和公益性。

从国家层面，政府购买服务已经进入制度化建设阶段; 从实践层面，各地政府在政府购 买服务方面都有过尝试 (例如: 北京、上海、广州、南京等地), 但大都集中经济比较发达的 地区为主, 要么采取“补需方”或者“补供方”的形式来具体实施。虽然在政策上思路大同小异, 遭遇的困境却各不相同。

\section{2. 基层政府购买养老服务的模式分析}

政府购买养老服务通过各地和各级政府的实践取得了蓬勃发展，其中政府通过购买养老 服务是提供养老服务的重要方式, 不仅可以调动社会组织参与养老服务的积极性, 而且可以 提高供给效率。所以, 本文重点对政府购买养老服务进行分析。根据相关学者的研究, 我们 可以将我国政府购买养老服务的模式分为以下三类:

\section{1 形式性购买, 即民办公助}

行为主体一方是政府，另一方是依附于政府而存在的社会组织。承接主体的组织和政府 之间有一种特殊的关系，通常保持“上下级”关系。这些组织因购买服务而存在，依赖购买资 金而生存。这种购买模式在我国公共服务供给中普遍存在，体现了政府“边培育边购买”的思 路。这种模式可以说是政府职能的延伸, 政府通过社会组织实现公共服务的供给。但是购买 协议通常是政府部门单方面意志的体现, 社会组织是政府意志的执行者。此种模式中政府的 决策与监督活动与社会组织的边界模糊, 资金的使用和监管都存在潜在的风险, 有些社会组 织成为相关政府职能部门私设的“小金库”。

\section{2 非竞争性购买, 即公办私营}

在这种模式下，社会组织是否拥有良好的社会声誉，是否具有专业优势是政府购买服务 选择时要考察的重要因素。社会组织相对比较独立，不是仅仅依赖政府的购买资金而生存， 必须独立承担购买过程中出现的责任。政府与社会组织通过相互协商来达成购买, 政府可以 根据养老服务的完成情况考虑来考核社会组织, 假如参与购买的服务的社会组织无法提供优 质的养老服务，可能会被其他社会替换掉。

\section{3 是竞争性购买, 即契约化购买}

政府通过公开招标的方式来选定适合竞争的社会组织，实现了“花小钱办大事”的效果。 参与购买服务的社会组织和政府部门相互独立, 不存在任何形式的依赖关系。招标的程序遵 
循公开、公平、公正的原则, 各类符合资质条件的社会组织均可报名参与。社会组织和政府 部门按照购买合同规范各方的权利和义务。通过持续有效的运转, 社会组织与政府部门可以 建立长期合作关系。

这三种模式在实际运作中并非完美无缺, 都存在着不同的问题。首先, 形式性购买无法 体现购买服务的优势, 权责关系边界模糊; 非竞争购买, 由于竞标程序的缺失, 其公平公正 性受到质疑; 竞争性购买虽然在购买框架上比较完备, 但是在购买过程的细节设计上还不完 备。例如: 存在着购买对象有限、成本核算太过草率、评价机制不够完善等问题。当然, 任 何模式都是在不断变化和发展的。地方政府可以根据本地实际, 探索切实可行的养老模式。

\section{3. 北京市顺义区政府养老服务的实践}

根据 2015 年底数据显示，北京市顺义区 60 周岁以上常住老年人为 14 万，占常住总人口 数的 $13.7 \%$; 60 周岁以上户籍人口 12.7 万, 占户籍人口总数的 $20.6 \%$, 也就是说, 每 5 个户 籍人口中就有一位 60 周岁以上老人。据近几年统计结果显示, 顺义区每年 60 周岁以上的老 年人以 5000 人/年的速度递增, 区域老龄化日趋加快, 养老服务的需求总量非常巨大。根据

《北京市居家养老服务条例》, 顺义区委区政府出台了《顺义区关于加快养老服务业发展的实 施意见》、《顺义区养老服务考评奖励办法》积极应对人口老龄化。整合资源, 主动布局, 实 现养老服务全覆盖。具体做法如下:

\section{1 建立完善的养老服务体系}

\subsection{1 建立居家养老补贴制度和政府购买养老服务制度}

居家养老补贴制度根据年龄、层次确定老年人优待范围、优待标准，逐步发展面向老年 人的普惠性优待项目。在顺义区, 为 80 周岁发放养老助残卡。此卡只能用于购买预防保健、 生活照料、居家护理、就医陪护、老年保险等养老服务。在 2015 年, 顺义区老龄办共发放 80 周岁及以上高龄津贴 960 万元, 为 90 周岁及以上老人发放医疗补助资金 109 万元。在顺 义区, 通过购买服务和志愿服务的方式, 实施居家养老服务工程。主要为城区 60 周岁以上独 居老年人提供“打扫卫生、洗衣服做饭和精神慰藉”三项免费服务。服务内容包括由“96156”社 区服务力量提供每周一次两小时为独居老年人提供的上门服务; 每周不少于 4 次为独居老人 提供精神关怀服务。为辖区的失独家庭提供每月 2 次, 每次 4 小时的生活服务、心灵慰藉服 务和开展健康讲座等服务。

3.1 .2 在城市社区充分发挥“政企合作”基层为老服务站

基层的为老服务站是通过政府和社会组织、企业的合作来实现。例如北京市顺义区便民 社区服务中心是一家由顺义区科委主管, 顺义民政注册的以社区服务为主的非盈利性社会组 织。为企事业单位、家庭提供服务。其中有与顺义区民政局合作战略“96156”，这是顺义区民 政局开通的民生服务热线, 并配备了专门的车辆, 遇到服务需求能够提供快捷、周到、专业 的服务。顺义区以基层社区为单位，建立了 222 个托老所为基层为老服务基站。如在张镇驻 马社区, 通过企业化管理和经营, 为周边老人提供入户照料、老年送餐、娱乐健身等低偿服 务。旺泉街道特十六局托老所通过与餐饮企业合作, 为本社区 60 岁以上的失独、空巢困难老 年人提供低偿午餐服务。

3.1 .3 在农村成立“政府支持”养老照料中心

在顺义区的农村建立了 8 家镇级养老照料中心, 以敬老院和养老照料中心辐射养老为主 的农村居家养老模式。在木林镇和杨镇的养老照料中心, 通过改建原有的民营养老机构基础 设施, 满足老人的养老服务需求。可提供教育培训、短期照料、助餐、助浴、助医、精神关 怀等服务。 


\section{2 培育和发展社会组织, 鼓励参与养老服务}

在北京市顺义区慈善协会的领导下成立北京市顺义区社会组织发展服务中心（这个中心 相当于社会组织的孵化器), 并积极鼓励社会组织参与养老服务。基层政府向社会组织购买服 务项目, 为特殊群体提供个性化服务。利用市场机制和政府购买的方式由服务商承接, 进行 专业化运营。2016 年, 政府共投入 990 万元，发挥政府息底保障的作用，安排了一批为老服 务项目, 将已成熟的项目转化为公共政策。例如: 顺义区政府与相关组织签订协议, 在医养 结合方面又有新探索。通过政府购买服务的方式为高龄、特殊老年人进行医疗巡诊; 通过民 办医疗机构为高龄老年人提供上门体检服务; 通过权威心理咨询机构为老年人提供心理健康 讲座和精神关怀服务; 通过试行家庭医生模式, 建立老年人居家养老健康档案, 推动老年人 动态就医。

\section{3 利用技术手段，构建“互联网+服务”的养老模式}

目前，在顺义区民政局登记注册的具有“互联网+服务”功能的民办非企业单位有 2 家。其 中顺义区的空港街道万科花园社区易来福居家养老中心，实现了线上线下的养老服务。易来 福利用“互联网+”模式, 打造智慧养老服务平台。通过远程健康监测、一键呼叫、手机 APP 等线上媒介搜集整合老人需求，在线下由专业服务队为老人提供日常家政、日间托管、医疗 健康、紧急求助、精神陪伴、文娱活动及定制延伸服务。利用“走出去”和“请进来”两种服务 和运营模式。“走出去”, 即社区老人可通过电话预约, 由专业化的服务人员到家中采集信息, 不仅可以提供家政服务，还可提供购物配药等生活服务。“请进来”即社区老年人可到日间照 料中心，享受日托养老服务。为老人建立健康检测卡，通过读卡器将老人的基本信息、血压、 血糖、心电图等相关数据传送到易来福养老服务平台上。子女也可通过手机 APP 软件及时掌 握父母健康状况。依托智能化技术手段使服务人员进入老人家庭工作实现了服务流程的即时 闭环管理, 有效降低了居家老人外请服务上门风险。通过为老年人提供专业化、规范化、标 准化和个性化的生活照料服务, 实现了居家养老管理的主动化和服务质量的可控化。“互联网 +居家养老”服务模式的运行，形成了一座“没有围墙的虚拟养老院”。

\section{4. 结论与讨论}

由于基层政府购买养老服务目前仍处在实践探索阶段，通过对北京市顺义区养老服务现 状的调研和分析, 本文得出以下结论:（1）基层政府向社会组织购买养老服务, 是政府行为 的创新。北京市基层政府面临非常艰巨的养老服务任务，其具体落实也非常复杂。面对庞大 的养老服务需求，增加养老服务供给，逐步使养老服务社会化。北京市已经形成了购买服务、 自费服务、志愿捐赠服务在内的多元化养老服务供给形式。（2）搭建覆盖城乡的三级养老服 务网络。建立以居家养老为基础, 以社区服务为依托, 以机构养老为补充的养老体系。在居 家养老方面, 通过适度普惠性政策手段, 实现居家养老服务的多样化。在社区服务方面, 建 立基层为老服务站、日间照料中心等社区养老机构。通过民生服务热线为老人提供周到的服 务。在机构养老方面, 加大民间养老机构的扶持力度, 整合现有医疗资源, 实现医养结合的 养老之路。（3）用信息化手段推动养老服务进程。构建“互联网+服务”、“互联网+文化”等智 慧养老模式。利用养老服务平台和手机 app 等技术手段, 让老人及家人足不出户就可以一键 下单。利用“互联网+平台 +020 ”的形式, 在互联网上发现服务需求, 然后在线下提供具体服务, 实现线上和线下的互动。利用“互联网+平台+智能化产品”的形式, 为老人提供精准的养老服 务。

\section{Reference}

[1] Wang Puqu. The government procurement of public services from social organizations of 
Chinese and global experience analysis [M] Beijing: Peking University press, 2012:208

[2] Lu. Study on the cooperation model between government and civil society organizations in the endowment service [J] scientific decision, 2009 (12)

[3]. Journal of China pension services review of public-private partnerships -- Reform and convergence mechanism of public institutions and government purchase service [J] Gansu Administration Institute, 2015 (3)

[4] Wang name, paradise. Analysis of the mode of Chinese civil society participation in public service purchase [J] Journal of Zhejiang provincial Party school, 2008 (3)

[5] the national office on aging. "13th Five-Year" national development and Planning Undertakings for the aged pension system of the [2017]13 [N] 2017-3-29 (Guangming Daily, 3) The people's Government of Beijing City, Beijing City 